\title{
Historical impact of technological change on the US mass media advertising expenditure
}

\author{
Mercedes Esteban-Bravo ${ }^{1}$, Jose M. Vidal-Sanz ${ }^{2}$, Gökhan Yildirim ${ }^{3}$
}

\begin{abstract}
Historically, the U.S. advertising industry has been experiencing enormous movements as a result of rapid advances in the media technology and the business cycle. In this paper, we study the historical behavior of the U.S. advertising industry, correcting for inflation. We find that the introduction of new media cause structural breaks in the mean growth rates of advertising expenditure for the incumbent media. In addition, we find that random components of media advertising spending follow a long-term equilibrium where the cross-elasticities across newer and older media can show substitution or complementarity patterns depending on the type of audience. We examine the influence of the economic conditions on the aggregated advertising expenditure, and on each media spending. We also measure the impact of the recent takeoff in mobile advertising.
\end{abstract}

Keywords: Media, Advertising expenditure, Structural Breaks, Cointegration. Run Title: Impact of technological change in media advertising

Highlights:

- New media introduction shifts down mean growth rates of incumbent ad expenditures.

- Long term equilibrium in advertising by media varies in substitution elasticities.

- Internet shifts all printed media trends, and is a stronger substitute for newspapers.

- Mobile shifts Internet \& printed media trends, is a strong substitute of newspapers.

- Total advertising is procyclical with respect to the business cycle in real terms.

${ }^{1}$ Corresponding author. Department of Business Administration. Universidad Carlos III de Madrid. C/ Madrid, 126. 28903 Getafe, Madrid, Spain. E-mail: mesteban@emp.uc3m.es

${ }^{2}$ Department of Business Administration. Universidad Carlos III de Madrid. C/ Madrid, 126. 28903 Getafe, Madrid, Spain. E-mail: jvidal@emp.uc3m.es

${ }^{3}$ Department of Management Science, Management School, Lancaster University, Bailrigg, Lancaster LA1 4YX, United Kingdom. E-mail: g.yildirim@lancaster.ac.uk 
"... look at history. TV [advertising] did not kill radio. Radio is doing just fine, even finding new ways to gain audiences. Cable TV did not kill over-the-air broadcast. The same, I believe, is true of print advertising. While digital options for marketing communications have negatively impacted the number of publications, total ad pages and revenue, print advertising remains a viable component of any media mix..." (Mark Semmelmayer, former chairman of Business Marketing Association).

"...we, however, think that advertising supported industries are undergoing a structural shift and, as such, think that newspapers and local TV revenue base will continue to face significant challenges..." (Imran Khan, JP Morgan analyst).

\section{Introduction}

The direct aim of new media technologies is facilitating alternative communication channels, but these advancements usually shake up the advertising industry inasmuch as changes in consumer behavior or economic conditions. As a consequence of technological progression in the media, the advertising industry has undergone tremendous shifts over most of the 20th and 21st centuries (Shankar and Balasubramanian 2009; Barnes et al. 2015; Kim and Lee, 2015). The golden age of newsprint media was between 1890 and 1920. From the 1920s, radio broadcast increasingly forced newspapers to re-evaluate their business, and the same happened in 1950 when TV broadcasting came on the media scene as well-known companies such as Procter \& Gamble and Unilever started to develop commercials. In subsequent years, the entry of TV was followed by Yellow Pages, cable, the Internet and more recently mobile. With the advent of Internet, the global advertising landscape has been almost redefined (Woo et al. 2014). Recent figures show that the U.S. firms spent, overall, $\$ 42.8$ billion and $\$ 49.5$ on the Internet in 2013 and 2014 respectively (Internet Advertising Bureau, 2014). The recent surge in online communities led many companies to spend substantially in social media advertising, resulting in 25.4\% estimated worldwide growth in 2015 (EMarketer, 2015). Induced by the widespread use of smartphones and high-tech mobile broadband technology (Shankar and Balasubramanian 2009; Shankar et al. 2010; Kim and Lee 2015), the mobile marketing is also on the rise, with $\$ 12.4$ billion spending in 2015 (Internet Advertising Bureau, 2014). Likewise, total spending in the sector has steadily growth until 2007 reaching \$233 billion, and suffered a moderate contraction after the last big depression, reaching $\$ 177.8$ billion in 2014 . But, expectations are for a partial recovery, reaching \$183 billion in 2015 and up to $\$ 197$ billion by 2017 (EMarketer, 2013). As the industry witnesses a moderation in the rate of growth, the battle between the traditional media such as newspapers, magazines, business papers and radio, and newer entrants such as Yellow Pages, cable, the Internet and mobile becomes more and 
more severe (Deleersnyder et al. 2002). ${ }^{4}$ Indeed, practitioners have been debating about the competition among different advertising media. The opening quotes illustrate the clash between views that old traditional media will remain viable and old media will face significant challenges. In general, the debates center on the long-term dynamic interrelationships at the macro level. For instance, is the long-term decline of newspapers due to the growth of Internet? Do the new media entries really create fundamental changes in the growth patterns of the incumbents, or is this view largely exaggerated? Should Internet be regarded as complementary or substitute media? Is TV still an important advertising medium? What role is the takeoff in mobile advertising playing? And more generally, to what extent does the competitive interplay differ between each pair of media?

Macroeconomic cycles also play a significant role in the dynamics of the advertising industry (Chowdhury, 1994). Even small changes in the ratio of advertising spending to the state of the economy can mean billions of dollars in advertising budgets, which in turn can affect media organizations critically (Lacy and Noh, 1997). On the advertisers' side, reactions to recessions are quite heterogeneous. While some corporations adopt proactive advertising during a recession, others favor cutting their communication investments (see Srinivasan et al. 2005, and Deleersnyder et al. 2009). However, the majority of companies cut their advertising budget during such times (Barwise and Styler, 2002, 2003; Picard, 2001). In spite of these theoretical and practical observations, little is known about the long run relationship between the aggregate level of advertising and the state of the economy when multiple new media introductions occur, as happened in the U.S. over the last century. Another issue which has not been explored thoroughly is the strength of each media to the performance of the economy, and more research is called for at country level (Tellis and Tellis, 2009).

This paper addresses the following questions: (i) Which is the long term equilibrium among all different media, traditional and new, in terms of advertising expenditure?, and more specifically, to what extent these media are substitutive or complementary in terms cross-elasticities?; (ii) What is the direct structural impact of new media introductions?; (iii) what is the long term equilibrium between macroeconomic cycles and advertising spending both at the aggregate level and for each media. This paper provides a rigorous answer to these

\footnotetext{
4 Scholars have used several distinct ways to categorize the traditional and new communication media. Thus, there is no unique way for conceptualizing the new media (Woo et al. 2014). A widespread description considers "new media" as those based on digital formats, but this description fits just into today's new media. All media where once new, and any list of new media will be changing over time. Therefore, understanding the impact of new media introduction requires us to look back at the last century's novelties.
} 
three questions by analyzing the U.S. advertising industry with a complete historical data from 1935 to 2013, comprising 11 different advertising media (newspapers, magazines, direct mail, business papers, outdoor, radio, TV, Yellow Pages, cable, the Internet and mobile). In particular, we estimate a Vector Error Correction Mechanism (VECM) model for cointegrated time series, accounting for multiple structural breaks caused by different media introductions. We also account for the relationship with the business cycle, especially the U.S. Gross Domestic Product (GDP) adjusted for inflation using the US Consumer Price Index (CPI). While some of these questions have been dealt with by previous research, the literature presents methodological limitations such as considering short-time horizons, and not distinguishing between introduction impact and long-term equilibrium. As a consequence, contradictory findings are often reported.

The paper is organized as follows: In the next section, we provide the literature review and background of the study. In Section 3, we introduce the data and the preliminary analyses on unit root and cointegration tests. In Section 4, we present the results of the disaggregated model in which each advertising media and the GDP are used (correcting for inflation). Also, we discuss the results of the aggregated model in which we use the total advertising spending and GDP. Finally, we conclude the paper with a summary of the main findings.

\section{Literature Review}

Our work embraces three different research streams in advertising-marketing literature as summarized in Table 1: (1) inter-media rivalry, (2) the relationship between Advertising in different media and GDP, and (3) the relationship between Aggregate Advertising Spending and GDP. Table 1 presents a synthetic overview of the three lines.

\section{Intermedia Rivalry}

This stream of literature examines if a particular advertising medium provoked competitive reactions from the incumbents (e.g. Saksena and Hollified, 2001), and whether the new arrival was a substitute or complimentary medium (e.g. Silk et al., 2001). For example, the empirical investigation of De Waal et al. (2005), based on cross-sectional telephone survey data, showed that the use of online newspapers negatively relates to the use of traditional newspapers. Allowing for multiple breaks at unknown points in time, Kornelis et al. (2008) explored to what extent competitive entry creates fundamental change in incumbents revenues for the Dutch TV advertising market. They found that new TV players did not cause a slowdown in the related markets of print and radio. Very recently, using survey data on media usage in South Korea, 
Woo et al. (2014) documented that internet negatively influenced print, TV and radio.

\section{Different Advertising Media and GDP}

A body of empirical research exists on the sensitivity of different advertising media to the state of the economy (e.g. Picard, 2008). For instance, Picard and Rimmer (1999) demonstrated that newspapers are strongly affected by economic downturns. Similarly, Van der Wurff et al. (2008) found that newspapers, magazines and outdoor advertising respond strongly to GDP while $\mathrm{TV}$, radio and cinema tend to grow regardless of whether economy is growing or contracting. Moreover, Deleersnyder et al. (2009) showed that magazines, newspapers, radio and TV expenditures have procyclical relationship with GDP.

\section{Aggregate Advertising and GDP}

The third stream of empirical research focuses on the impact of overall economic performance on total advertising spending (see Jones 1985; Callahan 1986). An early work by Swerdlow and Blessios (1993) showed a strong and positive relationship between advertising expenditures and general economic activity, GNP. Van der Wurff et al. (2008) found that advertising expenditures tend to increase with the economy. Likewise, Deleersnyder et al. (2009) showed that advertising spending is adjusted in response to general economic conditions and that average co-movement elasticity between advertising and GDP is 1.4.

Although all these studies provided valuable insights into the competitive interplay between different advertising media as well as advertising's sensitivity to the overall economic performance, they have several limitations. In general, they consider shorter time observation windows that limit the generalizability of the findings, and in many cases researchers seem unconcerned with cointegration and non-stationarity of the analyzed series. In addition, none of these articles take into account the structural breaks caused by new media introductions. Previous research is also limited because it does not take into account the long-term equilibrium between advertising expenditure on the different media after the structural breaks have been removed. Even more importantly, the literature has not estimated the long-run equilibrium cross elasticities between each different media. 
Table 1. Literature review

\begin{tabular}{|c|c|c|c|c|}
\hline \multirow{2}{*}{\multicolumn{5}{|c|}{ Intermedia Rivalry }} \\
\hline & & & & \\
\hline Silk et al. (2001) & $\begin{array}{l}\text { Is Internet substitute or } \\
\text { complimentary medium? }\end{array}$ & $\begin{array}{l}\text { Dataset of } 28 \text { cross elasticities } \\
\text { among different media, reported } \\
\text { by the same authors in } 1997 .\end{array}$ & Probit Model & $\begin{array}{l}\text { Internet looms as a potential } \\
\text { substitute or complement for all of } \\
\text { the major categories of existing } \\
\text { media. }\end{array}$ \\
\hline Saksena and Hollied (2002) & $\begin{array}{l}\text { Is the decline in newspapers' growth } \\
\text { due to the growth of Internet? }\end{array}$ & $\begin{array}{l}\text { Telephone survey data of } \\
\text { publishers of daily newspapers } \\
\text { in a single state in the } \\
\text { Southeastern United States in } \\
\text { 2001. }\end{array}$ & Correlation Analysis & $\begin{array}{l}\text { Managers in the Newspaper } \\
\text { industry had approached the } \\
\text { process of adopting the internet as } \\
\text { an emerging technology in a } \\
\text { haphazard fashion. }\end{array}$ \\
\hline De Waal et al. (2005) & $\begin{array}{l}\text { Is there any impact of online } \\
\text { newspapers on traditional } \\
\text { newspapers? }\end{array}$ & $\begin{array}{l}\text { Telephone survey data obtained } \\
\text { from the Dutch population in } \\
2002 \text {. }\end{array}$ & Correlation Analysis & $\begin{array}{l}\text { The use of online newspapers } \\
\text { negatively relates to the use of } \\
\text { print newspapers among the } \\
\text { young. Online newspaper reading } \\
\text { is accompanied by Radio and TV. }\end{array}$ \\
\hline Kornelis et al. (2008) & $\begin{array}{l}\text { Did competitive entry by different } \\
\text { commercial TV channels affect the } \\
\text { other TV, Radio and Print incumbents? }\end{array}$ & $\begin{array}{l}\text { Dutch advertising market in the } \\
\text { period of } 1990 \text { to } 1998 .\end{array}$ & $\begin{array}{l}\text { Unit Root testing procedure } \\
\text { under unknown endogenous } \\
\text { breaks }\end{array}$ & $\begin{array}{l}\text { Private TV incumbents revenues } \\
\text { was slowed by the entry of new TV } \\
\text { players, but such a slowdown was } \\
\text { not experienced in the related } \\
\text { markets of print and radio } \\
\text { advertising. }\end{array}$ \\
\hline Woo et al. (2014) & $\begin{array}{l}\text { What is the effect of new media on } \\
\text { the old media usage? }\end{array}$ & $\begin{array}{l}\text { Data via Media Consumer } \\
\text { Research Survey with } 6000 \\
\text { respondents in } 2011 \text { in South } \\
\text { Korea. }\end{array}$ & $\begin{array}{l}\text { Multiple Discrete-Continuous } \\
\text { Extreme Value (MDCEV) } \\
\text { model }\end{array}$ & $\begin{array}{l}\text { Internet neatively influenced old } \\
\text { media (Print, TV and Radio). Smart } \\
\text { mobile media had a synergistic } \\
\text { effect on TV use. }\end{array}$ \\
\hline \multicolumn{5}{|c|}{ Different Advertising Media and Economy } \\
\hline Picard and Rimmer (1999) & $\begin{array}{l}\text { What is the impact of recession on US } \\
\text { newspaper firms? }\end{array}$ & $\begin{array}{l}\text { Data from } 15 \text { publicly traded } \\
\text { companies before and after the } \\
\text { recession (1990-1991) }\end{array}$ & $\begin{array}{l}\text { Correlation and regression } \\
\text { analyses }\end{array}$ & $\begin{array}{l}\text { Newspapers are strongly affected } \\
\text { by economic downturns. }\end{array}$ \\
\hline Picard (2008) & $\begin{array}{l}\text { Is there any link between newspaper } \\
\text { advertising spending and GDP? }\end{array}$ & $\begin{array}{l}\text { The GDP and Newspaper } \\
\text { advertising expenditures data } \\
\text { compiled from US Department of } \\
\text { Commerce and Newspaper } \\
\text { Association of America for the } \\
\text { period of 1950-2005. . }\end{array}$ & $\begin{array}{l}\text { Simple graphical trend } \\
\text { analysis + correlations }\end{array}$ & $\begin{array}{l}\text { The relationship between } \\
\text { newspaper advertising and GDP is } \\
\text { weakening. Newspaper } \\
\text { advertising will decline in the } \\
\text { future. }\end{array}$ \\
\hline Van der Wurff et al. (2008) & $\begin{array}{l}\text { How do different advertising media } \\
\text { respond to macroeconomic } \\
\text { development? }\end{array}$ & $\begin{array}{l}\text { Macroeconomic data and } \\
\text { advertising expenditure data for } \\
\text { developed western economies } \\
\text { obtained from UN Statistical } \\
\text { Yearbook and World Advertising } \\
\text { Research Center's (WARC) for } \\
\text { the period of } 1987-2000 \text {. }\end{array}$ & Multiple Regression Analysis & $\begin{array}{l}\text { Newspapers, Magazines and } \\
\text { Outdoor advertising respond } \\
\text { strongly to GDP. TV, Radio and } \\
\text { Cinema tend to grow regardless of } \\
\text { whether economy is growing or } \\
\text { contracting. }\end{array}$ \\
\hline Deleersynder et al. (2009) & $\begin{array}{l}\text { Are Magazines, Newspapers, Radio } \\
\text { and TV expenditures related to overall } \\
\text { economic activity? }\end{array}$ & $\begin{array}{l}\text { Advertising data from the World } \\
\text { Advertising Research Center and } \\
\text { ZenithOptimedia. GDP data from } \\
\text { the } \\
\text { United Nations' Statistics } \\
\text { Division. } 25 \text { years of data in } 37 \\
\text { countries. } \\
\end{array}$ & $\begin{array}{l}\text { Time series-business cycle } \\
\text { filtering }\end{array}$ & $\begin{array}{l}\text { All Magazines, Newspapers, Radio } \\
\text { and TV expenditures have } \\
\text { procyclical relationship with GDP. }\end{array}$ \\
\hline \multicolumn{5}{|c|}{ Aggregate Advertising and Economy } \\
\hline Swerdlow and Blessios (1993) & $\begin{array}{l}\text { A model for predicting advertising } \\
\text { expenditures }\end{array}$ & $\begin{array}{l}\text { Data gathered on } 15 \text { industries } \\
\text { from Compustat database. }\end{array}$ & Multiple Regression Analysis & $\begin{array}{l}\text { There is a strong relationship } \\
\text { between advertising expenditures } \\
\text { and general economic activity } \\
\text { (GNP) }\end{array}$ \\
\hline Van der Wurff et al. (2008) & $\begin{array}{l}\text { Is there any relationship between } \\
\text { economic growth and advertising } \\
\text { expenditures for different media in } \\
\text { different countries? }\end{array}$ & $\begin{array}{l}\text { Macroeconomic data and } \\
\text { advertising expenditure data for } \\
\text { developed western economies } \\
\text { obtained from UN Statistical } \\
\text { Yearbook and World Advertising } \\
\text { Research Center's (WARC) for } \\
\text { the period of } 1987-2000 \text {. } \\
\end{array}$ & Multiple Regression Analysis & $\begin{array}{l}\text { Advertising expenditures tend to } \\
\text { increase with the economy. }\end{array}$ \\
\hline Deleersynder et al. (2009) & $\begin{array}{l}\text { Is advertising sensitive to business } \\
\text { cycle fluctuations? }\end{array}$ & $\begin{array}{l}\text { Annual advertising data obtained } \\
\text { from the World Advertising } \\
\text { Research Center and } \\
\text { ZenithOptimedia. GDP data from } \\
\text { the } \\
\text { United Nations' Statistics } \\
\text { Division. } 25 \text { years of data in } 37 \\
\text { countries. }\end{array}$ & $\begin{array}{l}\text { Time series-business cycle } \\
\text { filtering }\end{array}$ & $\begin{array}{l}\text { Advertising spending is adjusted in } \\
\text { response to economic conditions. } \\
\text { Average comovement elasticity } \\
\text { between advertising and GDP is } \\
\text { 1.4. }\end{array}$ \\
\hline
\end{tabular}




\section{Data and exploratory analysis}

There are several sources to compile data for the U.S. advertising expenditure. The first source is from Robert J. Coen who worked for McCann-Erickson, a global advertising agency. He compiled the data from 1948 to 2007 . His figures are based mainly on private sources such as Newspaper Association of America (NAA), A.C. Nielsen Company, Direct Mail Advertising Association, Outdoor Advertising Association etc. His advertising data were published in the U.S. Census Bureau's Historical Statistics of the United States. Thus, his dataset is consistent with the one from the U.S. Census Bureau, which comes from statistically representative surveys of firms. Dr. Douglas A. Galbi, economist at Federal Communications Commission augmented the Coen's data for the period 1919-1947. He also used some private data sources as well as his own estimates, which are consistent with Cohen's data for 1948-2007. The categories are mutually exclusive, i.e. the newspaper category does not include the Internet-based newspapers which are captured by the Internet category. Since the original Coen's dataset is until 2007, we extended it until 2013 by resorting to different sources, including Internet Advertising Bureau (IAB), Winterberry Group, Emarketer.com and United States Census Bureau. The extended data shows consistency with the previous records, except for the Internet for which Cohen seems to infra estimate the figures by using other sources. Consequently, we adopt IAB compilations for this variable as well as for mobile advertising. As a result, the final version of the compiled dataset covers the yearly data from 1919 to 2013 and contains the advertising expenditure on the following media: newspapers, magazines, direct mail, business papers, billboards, out of home, Yellow Pages, radio, television, broadcast, cable, the Internet, mobile, and total advertising. We added the advertising expenditure on 'out of home' and 'billboards' as the former was the antecedent of the latter, and called the new variable 'outdoor'. We followed the same approach for 'television' and 'broadcast', and called the final variable TV. Due to the evolution of the industry, advertising agencies used different names for these categories, but the underlying understanding of the specific category remained the same. Mobile advertising was introduced in the late 1990s, but did not receive significant attention until 2010 when IAB started to track it as a separate media. We have also obtained the nominal GDP and labor force variables from the U.S. Department of Commerce, Bureau of Economic Analysis and Bureau of Labor Statistics for the period of 1929 and onwards in order to account for the impact of economic crisis and expansions in the advertising industry. To adjust for inflation, we also consider an overall price index. In particular, we use the CPI with base year 2009. 
Finally, our dataset comprises the following variables: newspapers, magazines, direct mail, business papers, outdoor, radio, TV, Yellow Pages, cable, Internet, mobile, total advertising, GDP, CPI, and labor force. We have chosen the time period 1935-2013 so as to have less missing variables in the system. Figure 1 plots the advertising expenditure series in their original levels. In general, we observe exponential trends in the series, however, after the year 2000, TV, newspapers and radio advertising spending show a decreasing pattern. By contrast, direct mail, cable and Internet advertising spending exhibit an increasing pattern. Outdoor advertising spending shows a step increase in 1999 which continues in the following periods. Direct mail reaches the maximum with 60,225 million dollars in 2007.

Figure 1: USA advertising Expenditures over time (in million \$)

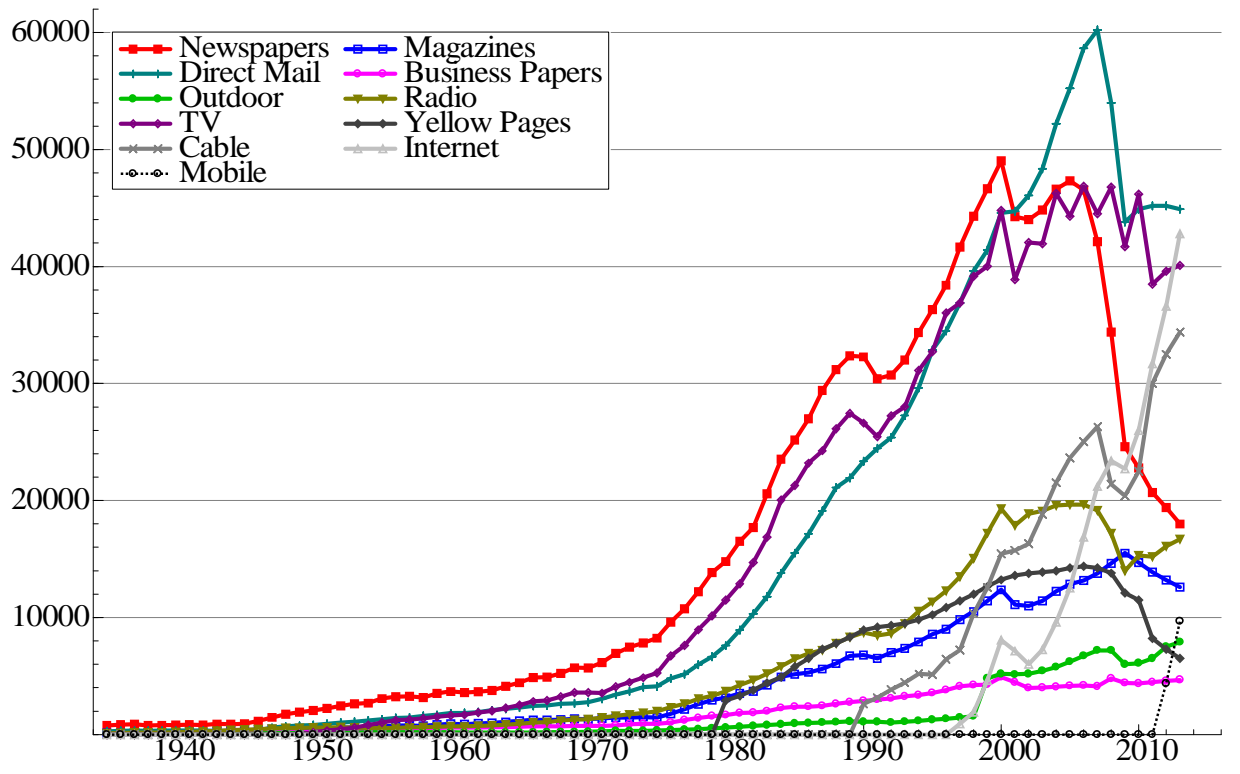

In order to make the series more linear, we took the natural logarithm for all variables. Besides, the logarithmic transformation is known to increase the distributional symmetry of nominal economic series. As can be seen from Figure 2, series in logarithm grow linearly and in parallel. The entry times of the four new media (TV, Yellow Pages, cable and the Internet) to the industry can be detected easily. For a given media, observations before the break point where the media takes-off are recorded as zeros. 
Figure 2: USA Advertising expenditure (million \$), GDP (million \$) and CPI in natural logarithms

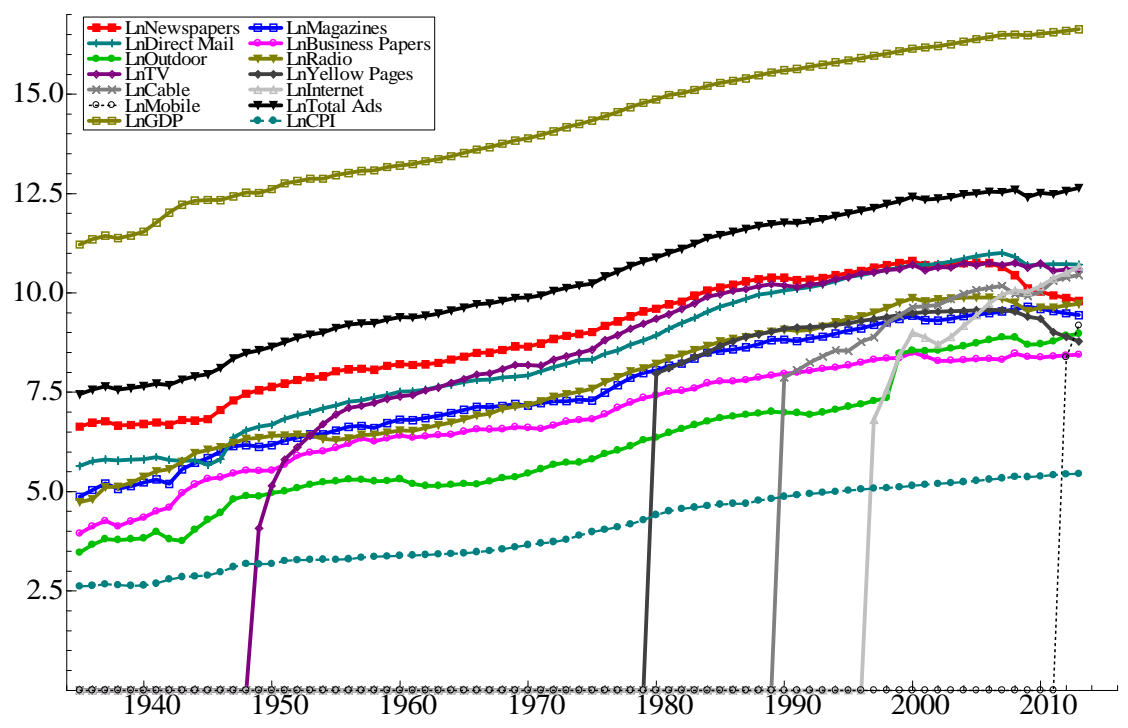

We conducted exploratory analysis, and tested for the presence of unit roots and cointegration relationships.

\section{Unit root tests}

Graphical inspection of Figure 2 suggests that the series are integrated of order one. Inspection of the Auto Correlation Function (ACF) plots for the original and the differentiated series also suggests that the series are $I(1)$. Additionally, we run several formal tests such as the Augmented Dickey Fuller (ADF) unit root tests (see Banerjee et al., 1993). This preliminary analysis suggests that $X_{t}$ is an $I(1)$ process. We also take into account that unit root tests for the considered media can be dramatically affected since structural breaks occur in the series (see Perron, 1989). In the ADF tests, we adopt two options: (i) only stochastic trend in the series, (ii) both deterministic trend and stochastic trend in the series. For both the aggregated and the disaggregated model, we find that the latter option is more appropriate since the coefficient of the deterministic trend is significant for most of the considered series. Table 2 summarizes the ADF unit root test results. For all variables, we fail to reject the null hypothesis of the ADF test that the series contains a unit root. Thus, the ADF unit root tests support our preliminary graphical findings. 
Table 2. ADF unit root tests

\begin{tabular}{|l|c|c|c|}
\hline & \multicolumn{2}{c|}{ ADF test result (p-value) } & \\
\cline { 2 - 4 } \multicolumn{1}{c|}{ Variables } & Intercept & Intercept and Trend & Conclusion \\
\hline In Newspapers & 0.473 & 1.000 & $\mathrm{I}(1)$ \\
\hline In Magazines & 0.373 & 0.964 & $\mathrm{I}(1)$ \\
\hline In Direct Mail & 0.747 & 0.901 & $\mathrm{I}(1)$ \\
\hline In Business Papers & 0.059 & 0.863 & $\mathrm{I}(1)$ \\
\hline In Outdoor & 0.946 & 0.514 & $\mathrm{I}(1)$ \\
\hline In Radio & 0.258 & 0.938 & $\mathrm{I}(1)$ \\
\hline In TV & 0.299 & 0.866 & $\mathrm{I}(1)$ \\
\hline In Yellow Pages & 0.828 & 0.639 & $\mathrm{I}(1)$ \\
\hline In Cable & 0.940 & 0.743 & $\mathrm{I}(1)$ \\
\hline In Internet & 0.974 & 0.918 & $\mathrm{I}(1)$ \\
\hline In Mobile & 0.990 & 0.997 & $\mathrm{I}(1)$ \\
\hline In Total Advertising & 0.551 & 0.989 & $\mathrm{I}(1)$ \\
\hline In GDP & 0.447 & 0.870 & $\mathrm{I}(1)$ \\
\hline In CPI & 0.875 & 0.702 & $\mathrm{I}(1)$ \\
\hline
\end{tabular}

\section{Cointegration}

In this section, we carry out an exploratory analysis for the cointegration of the considered variables listed in Table 2. Cointegrating tests can also be affected dramatically by the presence of structural breaks (see, Johansen, 2000). More specifically, to determine the rank of the cointegrating matrix $\beta$, we adopt the following sequential hypothesis testing. By using STATA-10 and OX version 3.4 (see Doornik, 2001), first, we test the null hypothesis that there is no cointegration against the alternative hypothesis that there is at least one cointegrating vector.

Table 3 displays the cointegration test results. In the disaggregated model, first we reject the null hypothesis that there is no cointegration since trace statistic (257.893) is greater than its critical value (233.130). Next, we test the null hypothesis that there is one cointegrating vector. We do not reject the null hypothesis as the trace statistic (186.555) is smaller than its critical value (192.890). Therefore, the conclusion for the disaggregated model is that there is one cointegrating vector. We follow the same approach for the aggregated model. The null hypothesis that there is no cointegration was rejected, but we do not reject the null hypothesis that there is one cointegrating vector because the trace statistic (3.262) is less than its critical value (3.760). Thus, there is one cointegrating vector in the aggregated model as well. 
Table 3. Johansen's cointegration test

\begin{tabular}{|c|c|c|c|c|}
\hline Maximum Rank & Log Likelihood & Eigenvalue & Trace Statistic & $5 \%$ Critical Value \\
\hline \multicolumn{5}{|c|}{ Disaggregated Model } \\
\hline 0 & 348.146 & - & 257.893 & 233.130 \\
\hline 1 & 383.815 & 0.599 & $186.5555^{*}$ & 192.890 \\
\hline 2 & 411.604 & 0.510 & 130.977 & 156.000 \\
\hline \multicolumn{5}{|c|}{ Aggregated Model } \\
\hline 0 & 256.714 & . & 19.499 & 15.410 \\
\hline 1 & 264.832 & 0.190 & $3.262 *$ & 3.760 \\
\hline 2 & 266.463 & 0.041 & & \\
\hline
\end{tabular}

\section{Methodology}

To derive empirical generalizations concerning advertising's sensitivity between media and to business cycles, and to test our hypotheses, we carried out a multivariate time series analysis allowing structural breaks associated with new media introductions. In particular, we build two models:

- Disaggregated model. Focusing on the structural impact of the new media introductions and the competitive interplay between advertising media, we study the long-run relationship between the logarithms of GDP, CPI, and advertising spending on the different media: newspapers, magazines, direct mail, business papers, outdoor, radio, TV, Yellow Pages, cable, the Internet and mobile. In other words, we consider a time series vector for $X_{t}=\left(\ln G D P_{t}, \ln C P I_{t}, \ln m_{t}^{\prime}\right)^{\prime}$ where the column vector $\ln m_{t}$ means logarithm of expenditures of different media.

- Aggregated model. To study the overall impact of macroeconomic cycles on advertising spending, we consider the aggregated model with structural breaks that provides a synthetic picture of the industry. In particular, we study the three-variate time series for $Y_{t}=\left(\ln G D P_{t}, \ln C P I_{t}, \ln \text { TotalAd }_{t}\right)^{\prime} \quad$ where TotalAds $s_{t}$ denotes total advertising expenditure.

Inspection of Figure 2 suggests that log-transformed series are integrated of order one, which essentially means that their growth rate is stationary, i.e. stable over time. Moreover, they seem to evolve in parallel driven by common trends according to certain long-term equilibrium defined by a cointegration relationship. This implies that the dynamics of this market can be represented by a refined VECM model. VECM models are standard in the time series literature 
and increasingly used in marketing (see Dekimpe et al. 1999). The interesting feature is that the common trend component between these series does not seem to change once the impact of a new introduction wears off. In other words, structural changes seem not to have an impact on the long run equilibrium (the cointegrating vector), but just on the short-term adjustments to the equilibrium (see Figure 2). This implies that the dynamics of this market should be represented by a refined VECM model with structural breaks in the dynamics but keeping the cointegration relationship stable. Ordinary VECM models are standard, but the refinement introducing structural breaks is not so widespread, and we have provided some technical explanations in the appendix for readers who are not familiar with these concepts.

\section{Model}

In the model we account for structural breaks caused by the takeoff of new media in the advertising industry using artificial variables. Let us assume that there are structural changes associated with the introduction of the TV, Yellow Pages, cable, the Internet and mobile media. Let $T=\left(T_{1}, \ldots, T_{k}\right)^{\prime}$ be the media introduction times (here $k=5$ ). We consider that the introduction times are deterministic, i.e. they are exogenous and we condition the process upon their value. The introduction of a new media may cause a permanent structural change in the growth rates of incumbent media (intervention analysis). Therefore, if the system grows at an autonomous vector rate $\gamma$ until the structural breaks occur, and at a different rate after the launch of a new media, then we can consider a deterministic component $\mu_{t}=E\left[X_{t}\right]$ given by

$$
\mu_{t}=\mu_{0}+\gamma t+\Phi F_{t}
$$

where $F_{t}$ is a deterministic vector with $j$-th coordinate $\max \left\{\left(t-T_{j}\right), 0\right\}$ equal to zero for $t<T_{j}$ and to $t-T_{j}$ for $t \geq T_{j}$, so that $F_{t}$ is formed by as permanent shifts starting at new media introductions. The elements of matrix $\Phi$ explain the cross-effects of all new media introduction on the deterministic component of other media. Then, for $t \geq 1$,

$$
\Delta \mu_{t}=E\left[\Delta X_{t}\right]=\gamma+\Phi D_{t},
$$

where $D_{t}$ is a deterministic vector of step functions, such that the $j$-th coordinate is defined as $D_{j t}=I\left(t \geq T_{j}\right)$ where $I\left(t \geq T_{j}\right)$ is the indicator function taking the value one if $t \geq T_{j}$ and zero otherwise. We impose some restrictions on the coefficient matrix $\Phi$. It must have a triangular media-structure, as we impose the restrictions that new media introductions in the advertising market do not affect investments on media launched in the distant future. 
Therefore, (i) TV introduction cannot cause any structural change in Yellow Pages since TV enters the market before Yellow Pages, (ii) TV and Yellow Pages cannot cause any structural change in cable series because TV and Yellow Pages enter the market before cable, (iii) TV, Yellow Pages and cable cannot cause any structural change in the Internet as it was launched after all of these media; and (iv) similarly, mobile is not affected by incumbent media.

The VECM representation indicates that the current increment in $X_{t}$ depends on previous deviations from the long-run equilibrium, the effect of deterministic components $D_{t}$, and previous corrections $\Delta X_{t-j}$

$$
\Delta X_{t}=\alpha\left(\beta^{\prime} X_{t-1}\right)+\sum_{j=1}^{p} \Gamma_{j} \Delta X_{t-j}+\left(\gamma+\Phi D_{t}\right)+\varepsilon_{t}
$$

We include the deterministic trend in the VECM model as $E\left[\Delta X_{t}\right]=\gamma$, based on our preliminary finding from the ADF unit root tests. Now $\beta$ is the cointegration vector, and $\beta^{\prime}\left(X_{t}-E\left[X_{t}\right]\right)=0$ is a long-term equilibrium relation between the coordinates in the vector $X_{t}$. The VECM models indicates that the change $X_{t}$ evolves driven by its lags $\left\{\Delta X_{t-j}\right\}$ with diminishing weights $\Gamma_{j}$, but it is also affected by previous deviation from the equilibrium relationship, $\beta^{\prime} X_{t-1}$, with corrections controlled by the parameters in $\alpha$.

The parameters $\left(\alpha, \beta, \Gamma_{1}, . ., \Gamma_{p}, c, \Phi, \Omega\right)$ are freely varying, but we have normalized $\beta$ to estimate the individual coefficients. The cointegrating rank of the last system is usually determined using Johansen's $(1988,1991,1995)$ maximum eigenvalue and trace tests. Johansen also considers the maximum likelihood estimators of the full model and the asymptotic distribution (for details, the reader is referred to Johansen et al. 2000 and Hungnes 2010). Pesaran et al. (2000) extend these ideas about deterministic components $\mu_{t}$ to models with exogenous process. Our model is estimated by maximum likelihood method using OX version 3.4 and GRaM (see Hungnes, 2005). We run the models up to four lags and compute the AIC and SIC criteria. Both information criteria suggest using one lag in the final analysis. Hence, to capture the short-term dynamics towards the identified long-term equilibrium, we estimate the VECM model with $r=1$ (one cointegrating vector) and $p=1$.

\section{Interpretation of coefficients}

Using the estimated $\beta^{\prime} s$, we can quantify the long-term sensitivity of advertising spending between media and to the state of the economy. Notice that the series in the vector $X_{t}$ are all 
in logarithms. Let us denote by $Z_{t}$ the original series, and $X_{t}=\ln Z_{t}$. If we differentiate the equilibrium $\beta^{\prime} \ln Z=0$, and we denote by $k$ the number of variables we obtain that:

$$
\beta_{i} \frac{d \ln Z_{1}}{d Z_{1}}+\ldots+\beta_{k} \frac{d \ln Z_{k}}{d Z_{k}}=0
$$

If we vary two components $i, j$ and set all the other variations to zero, then the cross elasticity between a pair of media becomes

$$
\eta_{i j}=\frac{d \ln Z_{i} / d Z_{i}}{d \ln Z_{j} / d Z_{j}}=-\frac{\beta_{i}}{\beta_{j}}
$$

where $\eta_{i j}$ refers to the elasticity of media $i$ expenditure with respect to that of media $j$. Note that the elasticities of each medium $i$ with respect to the GDP is simply $-\beta_{i}$, because of normalization $\beta_{G D P}=1$. The parameter $\eta_{i j}$ is interpreted as an $1 \%$ increase of expending in media $i$ results in $y_{j} \%$ increase in media $j$ in the long run equilibria. The reverse elasticity is $\eta_{j i}=1 / \eta_{i j}$. This is a measure of how one media substitutes another in the long run equilibrium. If $\eta_{i j}>0$ both media are complementary in the long run, if $\eta_{i j}<0$ then $i$ and $j$ are substitutive media. Notice that when there are deterministic components, the elasticity interpretation applies to the stochastic deviations from the trends and or structural changes. The elasticities must not be interpreted from a causal perspective, rather as association relationships.

\section{Correcting for inflation}

Monetary time series are typically deflated by dividing its values by that of an overall price index series; in this study we use the CPI. Deflated variables are described as "real" and the original ones as "nominal". In this section we analyze the data adjusting from inflation. We argue that for a log-linear model, one can equivalently introduce the price index as an additional regressor. If the deflated series are cointegrated, the long term equilibrium in real terms is given by

$$
\ln \left(\frac{G D P_{t}}{C P I_{t}}\right)+\beta_{1} \ln \left(\frac{A_{1 t}}{C P I_{t}}\right)+\ldots+\beta_{k} \ln \left(\frac{A_{k t}}{C P I_{t}}\right)
$$

(where the coefficient of deflated GDP is normalized to one) is equivalent to the relationship

$$
\ln G D P_{t}+\beta_{1} \ln A_{1 t}+\ldots+\beta_{k} \ln A_{k t}+\beta_{\pi} \ln C P I_{t}
$$

when $\beta_{\pi}=-\left(1+\beta_{1}+\ldots+\beta_{k}\right)$, so that instead of deflating we can use nominal variables 
together with CPI all in logarithms. But it is preferable not to enforce the over-identifying condition that the cointegration coefficients add one. Inflation is a complex phenomenon, and the stochastic co-trends between CPI and nominal advertising expenditure can vary across media, so that it is more flexible to allow for a free coefficient $\beta_{\pi}$ Therefore, we build a VECM considering directly a cointegration relationship in $\left(\ln G D P_{t}, \ln C P I_{t}, \ln A_{1 t}, \ldots, \ln A_{k t}\right)$, just with the normalization constraint that GDP has unit coefficient. By introducing the logarithm of CPI in the nominal model, we change the interpretation of the ratios $\eta_{i j}=-\beta_{i} / \beta_{j}$ which can be directly interpreted as long term crossed-elasticities ceteris paribus with respect to $\ln C P I_{t}$, so that we are evaluating real effects cleaned from price index variations. The technique of introducing a regressor to correct in variations from third variables is very common (e.g., it is applied in hedonic regressions). Another advantage of our approach is that we can compute the elasticity of advertising in a media $A_{k t}$ with respect to the CPI as a ratio $-\beta_{k} / \beta_{\pi}$. In this approach, the structural change coefficients reporting changes in $E\left[\Delta \ln A_{k t}\right]$ or $E\left[\Delta \ln G D P_{t}\right]$ caused by new media introductions are all computed in nominal terms, but now we also have the effect of media introductions on $E\left[\Delta \ln C P I_{t}\right]$. Therefore, we can obtain the structural changes in real terms by subtracting both effects, since

$$
E\left[\Delta \ln \left(\frac{A_{k t}}{C P I_{t}}\right)\right]=E\left[\Delta \ln A_{k t}\right]-E\left[\Delta \ln C P I_{t}\right],
$$

We follow a similar approach in the aggregated model. To correct for inflation, instead of the cointegration relationship

$$
\ln \left(\frac{G D P_{t}}{C P I_{t}}\right)+\beta_{T A} \ln \left(\frac{\operatorname{TotalA}_{t}}{C P I_{t}}\right),
$$

we consider the equivalent expression $\ln G D P_{t}+\beta_{T A} \ln \left(\right.$ TotalA $\left._{t}\right)+\beta_{\pi} \ln C P I_{t} \quad$ (without imposing the constraint $\beta_{\pi}=-\left(1+\beta_{T A}\right)$, for the same reasons as in the disaggregated model).

\section{Disaggregated model with structural breaks}

Central questions about the introduction of a new medium are whether (i) it captures audience from incumbent media so that advertising expenditures are redirected from older media towards the new one; or, (ii) it satisfies users' complementary needs with respect to old media, and new media is making a positive impact in the ability of old media to attract advertising spending. In this section, we study which of these two possibilities hold for each considered 
media. Addressing this question is not trivial. We have found that there are two different components. New media introductions can have a systematic effect on deterministic (mean) trends of previously established media (this structural change is captured by dummy coefficients) and there the stochastic trends which may change direction unpredictably, but obey a long run equilibrium (cointegration relationship). Stochastic advertising trends in all media tend to keep this balance in the long term, imposing a stable type of contemporaneous elasticity across advertising expenditure of different media.

\section{The structural impact of the new media introductions}

As different media entered the market at different points in time, we should consider structural breaks for the whole system. In other words, whenever a new media starts to be exploited by the advertising industry, its structural impact should be taken into account for the entire industry. As discussed earlier, persistence and cointegration tests can be dramatically affected by the presence of structural breaks. Structural breaks typically have little effect on the size of the usual cointegration tests, but they affect the power of the tests. There is a significant amount of literature that focuses on cointegration under known or unknown structural breaks. Maximum likelihood procedures have greater power than the Dickey-Fuller based cointegration tests (see Johansen 1991, 1994). The Johansen test requires modeling the break, but this is less restrictive in our context because the break time is observed. Next, we follow the Johansen $(1991,1994)$ framework to estimate the impact of new media introductions on advertising dynamics (see the appendix for a short introduction).

When introducing a new medium, there is an immediate direct effect in the expected logarithmic growth rates of the incumbent media nominal advertising, nominal GDP and CPI. These "introduction" effects are quantified by the estimates of the coefficients of the matrix $\Phi$ (rows in this matrix refer to media introductions, columns to affected variables).

Table 4 reports that, most media introductions make a statistically significant impact on the nominal growth rate of the nominal GDP (the exceptions are TV which was non-significant, and cable with a negative impact), and negative on the CPI (the only exception is Yellow Pages) probably because new media helped to increased competition through advertising and this in turn helped to reduce prices growth rates. Subtracting the first two columns, one obtains the effect on real GDP which are positive, except for cable. The structural changes in the advertising industry are also clear. The introduction of TV had a negative small impact over all media, this change is statistically significant in all cases except for direct mail. The entrance of Yellow Pages caused a positive small impact on all media (but in a few cases it is not 
significant). By contrast, Cable had a negative effect on all incumbents, moderate on yelow pages (-1.072), TV (-0.999) and small in all others. The Internet takeoff had a strong negative impact on Yellows Pages (-1.146) and a smaller negative impact on all the others (the effect on newspapers is -0.411). The takeoff of mobile has had a small effect on all previous media, and more significant on the print media. Since little time has passed after the mobile takeoff, future research may perhaps review this result adding more data.

\section{Table 4. The estimates of media introduction dummy coefficient}

\begin{tabular}{|c|c|c|c|c|c|c|c|c|c|c|c|c|}
\hline Introduction $\backslash \Delta \log$ of & GDP & CPI & Newspapers & Magazines & Direct Mail & Business Paper & Outdoor & Radio & TV & Yellow Pages & Cable & Internet \\
\hline TV & 0.013 & $-0.012^{* *}$ & $-0.032^{* *}$ & $-0.036 * * *$ & -0.011 & $-0.031^{* *}$ & $-0.104 * * *$ & $-0.044 * * *$ & 0.000 & 0.000 & 0.000 & 0.000 \\
\hline Yellow Pages & $0.053 * * *$ & $0.047^{* * *}$ & $0.100 * * *$ & $0.104 * * *$ & $0.109 * * *$ & $0.073 * *$ & $0.137^{* * *}$ & $0.115^{* * *}$ & 0.054 & 0.000 & 0.000 & 0.000 \\
\hline Cable & $-0.337^{* * *}$ & $-0.269 * * *$ & $-0.542 * * *$ & $-0.517^{* * *}$ & $-0.469 * * *$ & $-0.467 * * *$ & $-0.781 * * *$ & $-0.549 * * *$ & $-0.996 * * *$ & $-1.072^{* * *}$ & 0.000 & 0.000 \\
\hline Internet & $0.213^{* * *}$ & $-0.179 * * *$ & $-0.411 * * *$ & $-0.341 * * *$ & $-0.351 * * *$ & $-0.342^{* * *}$ & $-0.478^{* * *}$ & $-0.398 * * *$ & $-0.720 * * *$ & $-1.146^{* * *}$ & -0.006 & 0.000 \\
\hline Mobile & $0.094^{* *}$ & $-0.083 * * *$ & $-0.170 * * *$ & $-0.209 * * *$ & $-0.147 * *$ & -0.116 & $-0.282 * *$ & -0.124 & -0.272 & -0.455 & -0.089 & -0.371 \\
\hline
\end{tabular}

\section{The competitive interplay between advertising media}

In this section, we examine fluctuations around the deterministic trends for all the considered variables. Due to the cointegration relationship, fluctuations tend to correct themselves to satisfy a long-term equilibrium, which determine underlying cross-elasticities $\left(\eta_{i j}\right)$ for all the considered variables. As lnCPI is included in the model, all elasticities are computed in a ceteris paribus context with respect to inflation, i.e. they have the interpretation of real effects. These elasticities have an association interpretation, not causality. We report these values in Table 5.

In particular the first column of Table 5 shows the general deviation of each media (in rows) with respect to its baseline (deterministic trend) in percentage, when the GDP deviates a $1 \%$ from its baseline trend. An expansion of the GDP is positive for all printed media (newspapers, magazine, business papers). In particular, it is stronger in newspapers $(2.75 \%)$ meaning that newspapers suffer intensively when there are GDP contractions of several percentage points as in the big depression. A 1\% GDP expansion has a negative effect on direct mail (-3.12\%) and outdoor $(-1.36 \%)$. A $1 \%$ GDP expansion has a positive effect on CPI (3.62\%) meaning that more intensive activity generates more inflation. The second column in Table 5 shows the impact of a $1 \%$ increase of CPI beyond the deterministic component over each media, most effects are relatively small.

If we consider the columns associated to the different media, each column shows the effect of a $1 \%$ baseline-deviation in that media over each of the media listed in rows (in real terms, as elasticities are computed ceteris paribus with respect to prices). Magazines is a substitute 
media with respect to newspapers $(-16.34 \%)$, has a positive impact on direct mail $(18.57 \%)$, and outdoor $(8.09 \%)$. Also business papers have a negative impact on newspapers $(-3.51 \%)$, and a positive on direct mail (3.99\%). By contrast, outdoor has a positive impact on newspapers $(2.02 \%)$ and a negative on direct mail (-2.3\%). Radio is negatively related to newspapers (-4.82\%) and positively to direct mail (5.48) and outdoor (2.39). TV is positively related to newspapers $(7.02 \%)$ and negatively to direct mail (-7.97\%). Yelow Pages has a positive effect on newspapers $(8.81 \%)$ and a strong negative effect on direct mail $(-10.02 \%)$ and moderate effect on outdoor $(-4.36 \%)$. Cable has a moderate negative effect on newspapers $(-3.30 \%)$. The Internet is an advertising channel substitute for newspapers, a $1 \%$ positive baseline-deviation will reduce that of newspapers in a $4.53 \%$. But the Internet has a positive effect on direct mail (5.15\%) and outdoor (2.24\%). Mobile has a strong negative effect on newspapers $(-12.57 \%$, even larger than the Internet), and a positive effect on direct mail $(14.29 \%)$ and outdoor $(6.22 \%)$. The effect of mobile on Internet is moderate and negative $(-2.77 \%)$. But the effects of mobile have to be considered with some caution. Mobile introduction is too recent, and the estimators are computed from a relatively small number of observations, so that the estimations for mobile elasticities are somewhat tentative. Notice that most media, especially digital media (Cable, Internet, and mobile) have a positive impact on the GDP, but TV and Yellow pages are negatively associated.

Table 5. Cross-elasticities of all media, GDP and CPI

\begin{tabular}{|c|c|c|c|c|c|c|c|c|c|c|c|c|c|}
\hline & GDP & $\mathrm{CPI}$ & Newspaper & Magazines & Direct Mail & Business Papers & Outdoor & Radio & TV & Yellow Pages & Cable & Internet & Mobile \\
\hline GDP & 1 & 0.28 & 0.36 & 5.95 & \begin{tabular}{|l|}
-0.32 \\
\end{tabular} & \begin{tabular}{|l|}
1.28 \\
\end{tabular} & -0.74 & 1.76 & -2.55 & \begin{tabular}{|l|}
-3.21 \\
\end{tabular} & 1.20 & 1.65 & 4.58 \\
\hline $\mathrm{CPI}$ & 3.62 & 1 & -1.32 & -21.56 & 1.16 & -4.63 & 2.67 & -6.36 & 9.26 & 11.63 & -4.35 & -5.98 & -16.59 \\
\hline Newspaper & 2.75 & -0.76 & 1 & -16.34 & 0.88 & -3.51 & 2.02 & -4.82 & 7.02 & 8.81 & -3.30 & -4.53 & -12.57 \\
\hline Magazines & 0.17 & -0.05 & -0.06 & 1 & 0.05 & -0.21 & 0.12 & -0.30 & 0.43 & 0.54 & -0.20 & -0.28 & -0.77 \\
\hline Direct Mail & -3.12 & 0.86 & 1.14 & 18.57 & 1 & 3.99 & -2.30 & 5.48 & -7.97 & -10.02 & 3.75 & 5.15 & 14.29 \\
\hline Business Papers & 0.78 & -0.22 & -0.28 & -4.65 & 0.25 & 1 & 0.58 & -1.37 & 2.00 & 2.51 & -0.94 & -1.29 & -3.58 \\
\hline Outdoor & -1.36 & 0.38 & 0.49 & 8.09 & -0.44 & 1.74 & 1 & 2.39 & -3.47 & -4.36 & 1.63 & 2.24 & 6.22 \\
\hline Radio & 0.57 & -0.16 & -0.21 & -3.39 & 0.18 & -0.73 & 0.42 & 1 & 1.45 & 1.83 & -0.68 & -0.94 & -2.61 \\
\hline TV & -0.39 & 0.11 & 0.14 & 2.33 & -0.13 & 0.50 & -0.29 & 0.69 & 1 & -1.26 & 0.47 & 0.65 & 1.79 \\
\hline Yellow Pages & -0.31 & 0.09 & 0.11 & 1.85 & -0.10 & 0.40 & -0.23 & 0.55 & -0.80 & 1 & 0.37 & 0.51 & 1.43 \\
\hline Cable & 0.83 & -0.23 & -0.30 & -4.95 & 0.27 & -1.06 & 0.61 & -1.46 & 2.13 & 2.67 & 1 & -1.37 & -3.81 \\
\hline Internet & 0.61 & -0.17 & -0.22 & -3.61 & 0.19 & -0.77 & 0.45 & -1.06 & 1.55 & 1.94 & -0.73 & 1 & -2.77 \\
\hline Mobile & 0.22 & -0.06 & -0.08 & -1.30 & 0.07 & -0.28 & 0.16 & -0.38 & 0.56 & 0.70 & -0.26 & -0.36 & 1 \\
\hline
\end{tabular}

We also check the actual versus predicted series pertaining to the disaggregated model. As can be seen from Figure 3, our model our model predictions fit the data well. 
Figure 3: Model fit (actual versus predicted)
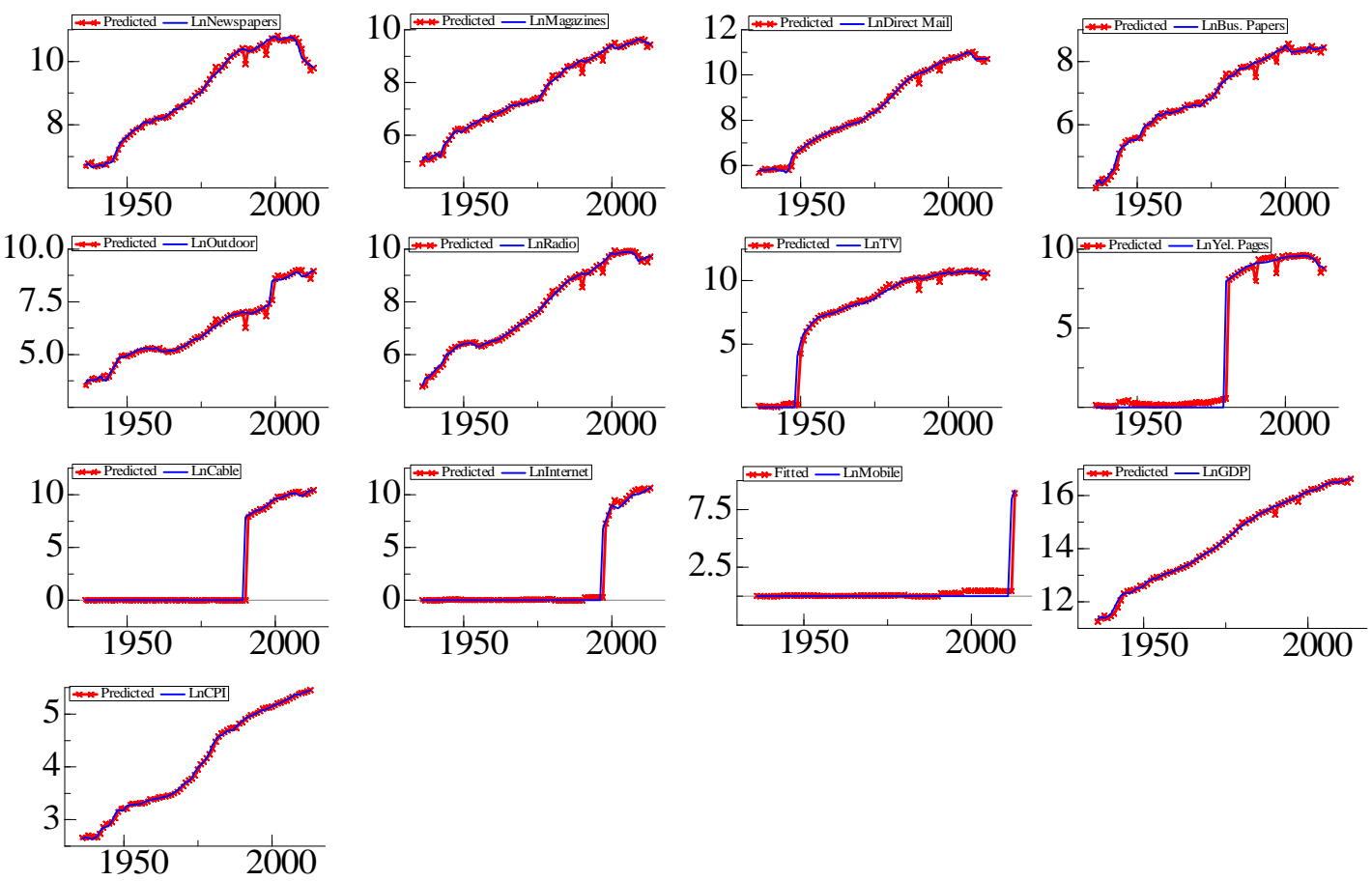

\section{Aggregated model with structural breaks}

To study the impact of economic developments and macroeconomic cycles on the advertising industry, we consider the aggregated model with structural breaks. In particular, we model the total advertising expenditure (Total Ads), CPI and GDP, all in logarithm. We also include the structural break dummies to see whether or not the new media affected the structure of the overall budget.

Our results show that none of the structural dummies are significant. In the aggregated model, our focus is given on the estimated cointegrating vector $\beta$ to examine whether the total advertising spending and GDP moves in the same direction in the long run. The estimated $\beta$ in Table 6 shows us the long-term elasticity since both variables are expressed in logarithm. As with the disaggregated model, the coefficient of Ln GDP is normalized to one. Thus, the long run elasticity of the total advertising spending with respect to GDP shows that an $1 \%$ expansion of the GDP will result in a $2.074 \%$ deviation of Total Ads with respect to its baseline in real terms. This finding suggests the evidence of a procyclical advertising spending in the U.S when the structural impact of the media introductions is considered. Furthermore, our 
result is in line with the literature that reports a positive relationship between the total advertising and the economy (see Jones 1985, Callahan 1986). When the ln CPI is not included in this model, the elasticity of Total Ads with respect to the GDP is $1.6597 \%$. This is a nominal impact, and it is similar to the 1.4 elasticity reported by Deleersnyder et al. (2009).

Table 6. Estimated cointegration parameters $\beta$ (Aggregated Model)

\begin{tabular}{|l|c|}
\hline In GDP & 1.000 \\
\hline In Total Advs & -2.074 \\
\hline In CPI & 1.9452 \\
\hline
\end{tabular}

Figure 4 shows the actual versus predicted series of the aggregated model. The plots demonstrate that our model predictions adjust the data quite well.

Figure 4. Model fit (actual versus predicted)

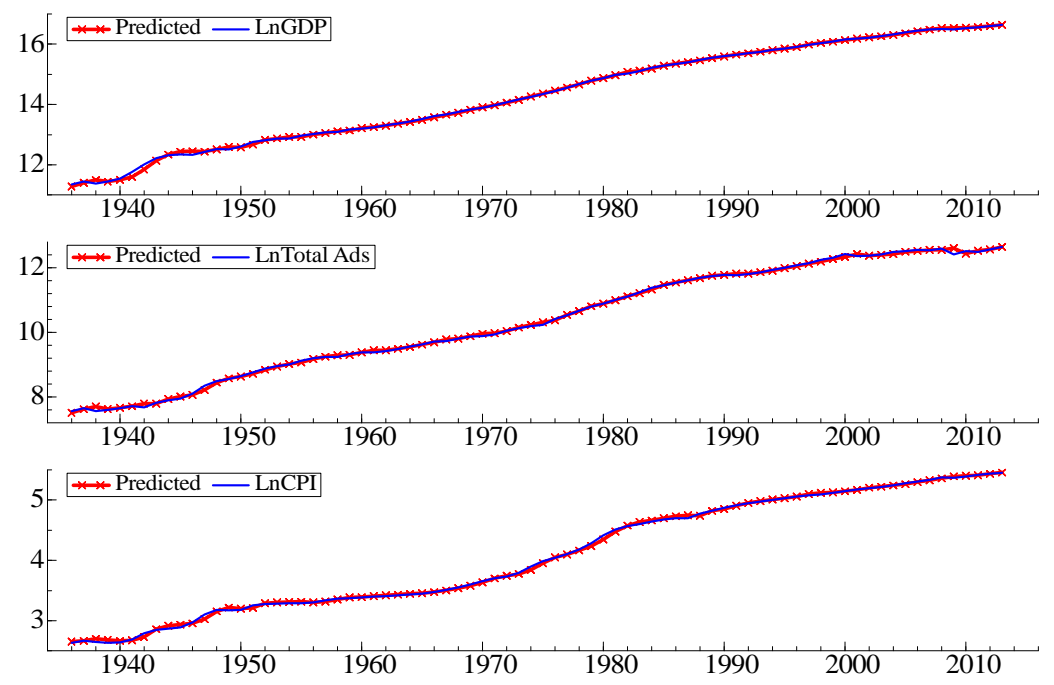

We have also estimated the aggregated model including the natural logarithm of labor in the VECM. In this model, the elasticity of labor force with respect to the GDP is $-0.096 \%$, meaning that a $1 \%$ of GDP expansion from its baseline is generally associated to a small reduction of labor with respect to its baseline, due to a substitution pattern of labor by capital factors. The elasticity of total advertising with respect to GDP is now $2.10 \%$ (ceteris paribus with respect to labor), larger than the $2.074 \%$ obtained when we do not control for labor variations. But the model with labor has a difficult interpretation in the dissagregated model. 


\section{Discussion and Conclusions}

Technological advancements in communication media have been having a profound impact on the advertising industry. The results of our analysis show that new media entries cause a structural break in the deterministic components of incumbent media. In addition, we observe a stable effect in random deviations from the baseline which evolve following a self-correcting mechanism to keep a long-term equilibrium where we can find substitution and complementarity patterns. For example, our results show that the Internet takeoff reduced moderately the baseline logarithmic growth rate of direct mail; indicating a systematic shift in advertising expenditure from direct mail towards the Internet. However, the elasticity of direct mail with respect to the Internet is positive, meaning that random departures from the baseline are shared by both media in the same direction. Internet takeoff reduced the baseline logarithmic growth rate of advertising expenditure for all the printed media, and the elasticity of printed media with respect to the Internet is negative. But, we observe some heterogeneity, i.e. newspapers' cross-elasticity is much bigger in absolute terms than that of magazines.

To measure all of these effects, we need a rich model capable of managing permanent shits and the equilibrium of stochastic fluctuations. We are able to address this problem in a more conclusive way than previous research because we study a large historical database of a key country in the development of communication technologies and advertising industry, and we use a sound methodology using a VECM model that allows for multiple structural breaks due to new media entries. In all models, we introduce CPI to control for inflation. Based on the patterns observed after the introduction of quite old and fairly new technological advances, we conclude that the introduction of new media generally has a negative permanent impact on the growth rates of advertising spending through incumbent media (just in few cases the impact is positive). But, the cross-elasticities can show a wider variety of patterns, depending on the type of audience reached by each media.

Our study also helps to quantify the challenged that mobile is posing on the Internet channels. The recent takeoff in mobile advertising has moderatly reduced the growth rate of the Internet advertising spending baseline. In adition, mobile advertising expansions from the baseline damages Internet media advertisers due to the negative cross-elasticity. There has been a debate about the extent to which mobile advertising means a threat to other digital media. Mobile devices have potential to connect individually targeted advertising with location, making a substantial business impact. The US mobile operator Verizon is about to acquire the online advertising platform AOL for $\$ 4.4 \mathrm{bn}$ (subject to regulatory approval) to accelerate the 
transformation. Mobile has also shifted printed media mean trends, but the stronger substitutive effect is over newspapers. A limitation in our data is that the mobile series is too short for a final analysis, as the takeoff of mobile media in the advertising industry is relatively recent. Mobile data limitations do not affect other parameters in the model. We have conducted all the analyses with and without the mobile series (using just an exogenous structural change dummy to account for its introduction), and there are not noticeable changes in results related to other variables. Therefore, we decided to keep mobile in order to compute cross-elasticities for mobile ads. But, the coefficients associated to mobile are somewhat tentative, and with more data, the estimations of these elasticities may vary.

With respect to the long term relationship between each advertising media and economy, we found that the total advertising moves in the same direction as GDP; i.e. it is pro-cyclical, which is in line with related literature (Jones 1985), Callahan 1986), and Deleersnyder et al. 2009). Correcting for inflation, the cross-elasticity is close to, but slightly larger than the estimations in nominal terms from previous studies.

\section{References}

Andras, T. L., and Srinivasan, S. S. (2003), "Advertising intensity and R\&D intensity: Differences across industries and their impact on firm's performance," International Journal of Business and Economics, 2(2), 167--176.

Banerjee, A., J. J. Dolado, J. W. Galbraith and D. F. Hendry (1993), Co-integration, error-correction, and the econometric analysis of non-stationary data, Advanced Textbooks in Econometrics. Oxford University Press, Oxford, UK.

Barnes, S.J., Mattsson J. and Hartley N. (2015), "Assessing the value of real-life brands in Virtual Worlds," Technological Forecasting \& Social Change, 92, 12-24.

Barwise, P. and Styler, A. (2002, 2003), "Marketing expenditure trends," London, UK7 London Business School/Havas Marketing Report, Retrieved from: http://faculty.london.edu/pbarwise/reportsandmonographs.htm.

Box, G.E.P. and G.C. Tiao (1977), "A Canonical Analysis of Multiple Time Series," Biometrika, 64, 355--365.

Bucklin, Randolph E., Oliver Rutz, and Michael Trusov (2009), "Metrics for the New Internet Marketing Communications Mix," in Malhotra, Naresh (ed.), Review of Marketing Research (Volume 5), M.E. Sharpe, 173-192.

Callahan, F. X. (1986), "Advertising and economic development," International Journal of Advertising, 5(3), 215--224.

Campos, Julia, Neil R. Ericsson and David F. Hendry (1996), "Cointegration Tests in the Presence of Structural Breaks," Journal of Econometrics, 70(1), 187-220.

Chowdhury, A.R. (1994), "Advertising expenditures and the macro-economy: Some new evidence," International Journal of Advertising, 13, 1-14.

Dekimpe, M. and D.M. Hanssens (1999), "Sustained Spending and Persistent Response: A New Look at Long-term Marketing Profitability," Journal of Marketing Research, November, p. 1-31. 
Dekimpe, Marnik G., Dominique M. Hanssens and Jorge M. Silva-Risso (1999), "Long-run Effects of Price Promotions in Scanner Markets," Journal of Econometrics, 89, 269-291.

Deleersnyder, B., Geyskens, I., Gielens, K., \& Dekimpe, M. G. (2002), "How cannibalistic is the Internet channel? A study of the newspaper industry in the United Kingdom and the Netherlands," International Journal of Research in Marketing, 19(4), 337-348.

Deleersnyder, Barbara, Marnik G. Dekimpe, Jan-Benedict E.M. Steenkamp and Peter S.H. Leeflang (2009), "The Role of National Culture in Advertising' s Sensitivity to Business Cycles: An Investigation Across Continents," Journal of Marketing Research, 46 (October), 623-636.

De Waal, E., Schoenbach, K., \& Lauf, E. (2005), "Online newspapers: A substitute or complement for print newspapers and other information channels?," Communications, 30, $55--72$.

Doornik, Jurgen A. (2001), Object-Oriented Matrix Programming Using Ox, 4th ed. London: Timberlake Consultants Press and Oxford.

EMarketer (2013), US Total Media Ad Spend Inches Up, Pushed by Digital, August, Retrieved from:

http://www.emarketer.com/Article/US-Total-Media-Ad-Spend-Inches-Up-Pushed-by-Digital/ 1010154

EMarketer (2015), Social Network Ad Spending to Hit \$23.68 Billion Worldwide in 2015, April, Retrieved from:

http://www.emarketer.com/Article/Social-Network-Ad-Spending-Hit-2368-Billion-Worldwid e-2015/1012357

Engle, Robert F. and Clive W. J. Granger (1987), "Co-integration and Error Correction: Representation, Estimation and Testing," Econometrica, 55(2), 251-276.

Fok, Dennis and Philip Hans Franses (2004), "Analyzing the Effects of a Brand Introduction on Competitive Structure Using a Market Share Attraction Model," International Journal of Research in Marketing, 21(2), 159-177.

Frankenberger, Kristina D. and Roger C. Graham (2003), "Should Firms Increase Advertising Expenditures During Recessions?", MSI Reports, 03 -115, 65-85.

Godes, David, Dina Mayzlin, Yubo Chen, Sanjiv Das, Chrysanthos Dellarocas, Bruce Pfeiffer, Barak Libai, Subrata Sen, Mengze Shi, and Peeter Verlegh (2005), "The Firm's Management of Social Interactions," Marketing Letters, 16 (3/4), 415-28.

Granger, Clive W. J. (1981) "Some Properties of Time Series Data and Their Use in Econometric Model Specification," Journal of Econometrics, 16, 121-130.

Hungnes, Håvard (2005), "Identifying the Deterministic Components in Cointegrated VAR Models using GRaM for Ox Professional- User Manual and Documentation," Working Paper.

Hungnes, Håvard (2010), "Identifying Structural Breaks in Cointegrated Vector Autoregressive Models," Oxford Bulletin of Economics and Statistics,72(4), 551-565.

Internet Advertising Bureau (2014), IAB Internet advertising revenue report, April, Retrieved from:

http://www.iab.net/media/file/IAB_Internet_Advertising_Revenue_FY_2014.pdf

Johansen, Soren (1988), "Statistical Analysis of Cointegration Vectors," Journal of Economic Dynamics and Control, 12, 231-254.

Johansen, Soren (1991), "Estimation and Hypothesis Testing of Cointegration Vectors in Gaussian Vector Autoregressive Models," Econometrica, 59, 1551-1580.

Johansen, Soren (1994), "The Role of the Constant and Linear Terms in Cointegration Analysis of Nonstationary Variables," Econometric Reviews, 13(2), 205-229.

Johansen, Soren (1995), Likelihood-Based Inference in Cointegrated Vector 
Autoregressive Models, Oxford University Press, New York.

Johansen, Soren and Katarina Juselius (1990), "Maximum Likelihood Estimation and Inference on Cointegration -- with Applications to the Demand for Money," Oxford Bulletin of Economics and Statistics, 52, 169-210.

Johansen, Soren, Mosconi Rocco and Bent Nielsen (2000), "Cointegration Analysis in the Presence of Structural Breaks in the Deterministic Trend," Econometrics Journal, 3, 216-249.

Jones, J. P. (1985), "Is total advertising going up or down?," International Journal of Advertising, 4(1), 47--64.

Kamber, T. (2002), "The brand manager's dilemma: Understanding how advertising expenditures affect sales growth during a recession," Brand Management, 10(2), 106-120.

Kim, K.Y. and Lee, B.G. (2015), "Marketing insights for mobile advertising and consumer segmentation in the cloud era: A Q-R hybrid methodology and practices," Technological Forecasting \& Social Change, 91, 78-92.

Kornelis, Marcel , Marnik G. Dekimpe, Peter S.H. Leeflang (2008), "Does Competitive Entry Structurally Change Key Marketing Metrics?," International Journal of Research in Marketing, 25, 173-182.

Lacy, S., \& Noh, G. Y. (1997), "Theory, economics, measurement, and the principle of relative constancy," Journal of Media Economics, 10(3), 3--16.

Linnett, R. (2002), "Magazines pay the price of TV recovery," Advertising Age, 73(35), $1-2$.

Low, George S. and Jakki J. Mohr (1999), "Setting Advertising and Promotion Budgets in Multi-Brand Companies," Journal of Advertising Research, 39 (January-February), 67-78.

Nijs, Vincent R., Marnik G. Dekimpe, Jan-Benedict E. M. Steenkamps, Dominique M. Hanssens (2001), "The Category Demand Effects of Price Promotions," Marketing Science, 20(1), 1-22.

Ostheimer, R. H. (1980), "Magazine advertising during recessions," Journal of Advertising Research, 20(6), 11-16.

Owen, Bruce M. (2000), The Internet Challenge to Television, Harvard University Press, Cambridge, MA.

Pauwels, K. and S. Srinivasan (2004), "Who benefits from store brand entry?," Marketing Science, 23(3), 364-390.

Perron, Pierre (1989), "The Great Crash, the Oil Price Shock and the Unit Root Hypothesis, Econometrica, 57, 1361-1401.

Pesaran, M. Hashem, Yongcheol Shin and Richard J. Smith (2000), "Structural Analysis of Vector Error Correction Model with Exogenous I(1) Variables," Journal of Econometrics, 97, 293-343.

Pfeiffer, M \& Zinnbauer, M. (2010), "Can Old Media Enhance New Media? How Traditional Advertising Pays off for an Online Social Network," Journal of Advertising Research, 50, 42-49.

Picard, R. G. (2001), "Effects of recessions on advertising expenditures: An exploratory study of economic downturn in nine developed countries," Journal of Media Economics, 14(1), $1-14$.

Picard, R. G. (2002), "U.S. newspaper ad revenue shows consistent growth," Newspaper Research Journal, 23(4), 21-33.

Picard, R. G. (2008), "Shifts in Newspaper Advertising Expenditures and Their Implications For The Future Of Newspapers," Journalism Studies, 9(5), 704-716.

Picard, R. G. and Rimmer T. (1999), "Weathering A Recession: Effects of Size and Diversification on Newspaper Companies," The Journal of Media Economics, 12(1), 1-18.

Saksena, S., \& Hollifield, C. A. (2002), "U.S. newspapers and the development of online editions," International Journal on Media Management, 4(2), 75-84. 
Shankar, V. and Balasubramanian, S. (2009), "Mobile Marketing: A Synthesis and Prognosis," Journal of Interactive Marketing, 23, 118-129.

Shankar, V., Venkatesh, A., Hofacker, C., and Naik, P. (2010), "Mobile Marketing in the Retailing Environment: Current Insights and Future Research Avenues," Journal of Interactive Marketing, 24, 111-120.

Shimp, A. Terence (2008), Advertising, Promotion and other aspects of Integrated marketing Communications, Eighth Edition, South-Western Cengage Learning, USA.

Silk, A. J., Klein, L. R., and Berndt, E. R. (2001), "The Emerging Position of the Internet as an Advertising Medium," Netnomics, 3(2), 129--148.

Srinivasan, Raji, Arvind Rangaswamy, and Gary Lilien (2005), "Turning Adversity into Advantage: Does Proactive Marketing During a Recession Pay Off?" International Journal of Research in Marketing, 22 (June), 109-125.

Swerdlow, R. A., and Blessios, V. I. (1993), "A model for predicting advertising expenditures: An inter-industry comparison," International Journal of Advertising, 12(2), 143-153.

Tellis, Gerard J. and Kethan Tellis (2009), "A Critical Review and Synthesis of Research on Advertising in a Recession," Journal of Advertising Research, 49(September), 304-327.

Van der Wurff, Richard, P. Bakker and R. G. Picard (2008), "Economic Growth and Advertising Expenditures in Different Media in Different Countries," Journal of Media Economics, 21, 28-52.

Van Heerde, Harald J., Carl F. Mela and Puneet Manchanda (2004), "The Dynamic Effect of Innovation on Market Structure," Journal of Marketing Research, 41(2), 166-183.

Woo, Jong Roul, Choi J.Y, Shin J. and Lee, Y. (2014), "The effect of new media on consumer media usage: An empirical study in South Korea," Technological Forecasting \& Social Change, 89, 3-11.

Yoon, Sung-Yoon and Joo-Ho Kim (2001), "Is the Internet More Effective Than Traditional Media? Factors Affecting Choice of Media," Journal of Advertising Research, November-December, 53-60. 


\section{Appendix}

Let us denote by $X_{t}$ a $\mathrm{R}^{k}$-valued stochastic time series process with unconditional mean $\mu_{t}=E\left[X_{t}\right]$, with $X_{t}=0$ with probability one for $t \leq 0$ (with finite autoregressive models sometimes other specific initial values are considered). The mean $\mu_{t} \in \mathrm{R}^{k}$ contains deterministic components (trends, intervention analysis components, etc.). Typically, but not always, the deterministic components are subtracted (if that is the case, then $\mu_{t}=0$ for all $t$ ). Then, we say that $\left\{X_{t}\right\}$ is integrated of order $d \in\{0,1,2, .$.$\} , also denoted as I(d)$, if each coordinate in $\Delta^{d} X_{t}$ follows an invertible stationary linear model, where $\Delta^{d}=(1-L)^{d}$ and $L$ is the lag operator $\left(L^{j} X_{t}=X_{t-j}\right)$. One of the most common cases in practice, is to find processes $X_{t}$ integrated of order one (in this case the components of the process tend to grow linearly as in the case of Figure 2). In particular, if $X_{t}$ is $I(1)$, then $\Delta X_{t}=\left(X_{t}-X_{t-1}\right)$ is stationary, and there are two possibilities (1) that $E\left[\Delta X_{t}\right]=0$ which means that $X_{t}$ evolves driven by a stochastic trend, or that $E\left[\Delta X_{t}\right]=\gamma$ which means that $\Delta X_{t}$ has a deterministic and/or a stochastic trend.

Example $A$ basic example of a determinist trend is the univariate process

$$
X_{t}=c+\gamma t+\varepsilon_{t}, \quad t=0,1,2, \ldots
$$

where $\varepsilon_{t}$ are i.i.d. random variables with zero mean and variance $\sigma_{\varepsilon}^{2}$, where clearly $\Delta X_{t}$ is stationary and $E\left[\Delta X_{t}\right]=\gamma$. A basic example of stochastic trend is the univariate process

$$
X_{t}=X_{t-1}+\varepsilon_{t}, \quad t=0,1,2, \ldots
$$

with $X_{0}=0$, with $E\left[\Delta X_{t}\right]=0$. Substituting recursively we obtain $X_{t}=\sum_{s=1}^{t} \varepsilon_{s}$, so that $E\left[X_{t}\right]=0$ but $\operatorname{Var}\left[X_{t}\right]=t \sigma_{\varepsilon}^{2}$ exploding as $t \rightarrow \infty$. The shocks $\varepsilon_{s}$ have a permanent effect in the future, this is why these processes are described as persistence. The name unit root is also used for these models (because they can be expressed as $(1-L) X_{t}=\varepsilon_{t}$, and $L=1$ is a root of the polynomial $(1-L)=0)$. We can have a combination of deterministic and stochastic trends, such as $X_{t}=c+\gamma t+X_{t-1}+\varepsilon_{t}$, where $E\left[\Delta X_{t}\right]=\gamma$, and the series in levels satisfies $E\left[X_{t}\right]=c+\gamma t$, and $\operatorname{Var}\left[X_{t}\right]=t \sigma_{\varepsilon}^{2}$. In all these examples $\left\{\varepsilon_{t}\right\}$ could follow a stationary linear process. 
Since the presence of linear trends (stochastic or deterministic) is important to understand the long-term dynamics of the process, there are many tests for $I(1)$, for an overview of unit root literature see Banerjee et al. (1993), and for a review of marketing applications see Dekimpe et al. (1999).

But we are interested in multivariate processes, and this introduces additional issues. When a multivariate process $\left\{X_{t}\right\}$ is $I(1)$, two possibilities emerge when we look at the whole system:

1) $\left\{X_{t}\right\}$ is jointly integrated of order $d$, that is, it is integrated of order $d$ and $(1-L)^{d} X_{t}$ follows an invertible vector Wold process

$$
\Delta^{d} X_{t}=B(L) \varepsilon_{t},
$$

with $\varepsilon_{t}$ white noise (actually $\varepsilon_{t}$ is zero for $t \leq 0$ ), $B(L)=\sum_{j=0}^{\infty} B_{j} L^{j}$ is a matrix-coefficient polynomial with $B_{0}=I$ (where invertibility means that the roots of $B(L)$ are outside the unit circle, and the process admits a convergent autoregressive representation), or

2) $\left\{X_{t}\right\}$ is cointegrated of order $d, b$ with $b \leq d$, and denote it by $C(d, b)$, that is the process is $I(d)$ and there are $r \leq k$ linear combinations defined by the $k \times r$ matrix $\beta$ such that $\beta^{\prime} X_{t}$ is jointly $I(d-b)$. The most important case is $d=b=1$. The idea goes back to Box and Tiao (1977), but it was popularized by Granger (1981). Cointegrated $C(1,1)$ variables can be expressed with Granger's representation Vector Error Correction Mechanism or VECM,

$$
\Delta X_{t}=\alpha\left(\beta^{\prime} X_{t-1}\right)+\sum_{j=1}^{\infty} \Gamma_{j} \Delta X_{t-j}+\gamma+\varepsilon_{t},
$$

where $\alpha$ is the $k \times r$ matrix of adjustment coefficients. The matrix of cointegrating vectors $\epsilon$ can be normalized as

$$
\beta=\left(\begin{array}{l}
I_{r} \\
\beta_{2}
\end{array}\right)
$$

where $I_{r}$ is an identity matrix, and $\beta_{2}$ is a $(k-r) \times r$ matrix of free parameters. For details see the path-breaking article by Engle and Granger (1987). For a detailed introduction see Banerjee et al. (1993).

There are several methodologies to work with VECM models. Probably the most widespread 
approach is the Johansen $(1991,1994,1995)$ framework which we will follow. In this context, we can introduce deterministic components $D_{t}$ to handle structural breaks. Instead of subtracting the deterministic components from $X_{t}$, Johansen (1995) directly assumes that $X_{t}$ follows an integrated $\operatorname{VAR} \boldsymbol{(}$ vector autoregression

$$
\Delta X_{t}=\Pi X_{t-1}+\sum_{j=1}^{p} \Gamma_{j} \Delta X_{t-j}+\left(\gamma+\Phi D_{t}\right)+\varepsilon_{t}
$$

The error vectors $\left\{\varepsilon_{t}\right\}$ are assumed to be Gaussian white noise $N(0, \Omega)$. Johansen considers the characteristic lags matrix polynomial

$$
A(L)=(1-L) I_{k}-\Pi L-\sum_{j=1}^{p} \Gamma_{j}(1-L) L^{j}
$$

In this context, if all the roots of the polynomial $|A(L)|$ are outside the unit circle (so that $A(1)=-\Pi$ has full rank), then the process is jointly integrated. However, if there are $(k-r)$ roots equal to 1 and the remaining roots are outside the complex unit circle, then $A(1)=-\Pi$ has rank $r$, and we can express $\Pi=\alpha \beta^{\prime}$, where $\alpha, \beta$ are $k \times r$ matrix of rank $r<k$, rendering the VECM representation (1). Note that the model (A1) can be also written in differences as

$$
\left(\Delta X_{t}-E\left[\Delta X_{t}\right]\right)=\alpha\left(\beta^{\prime} X_{t-1}-E\left[\beta^{\prime} X_{t-1}\right]\right)+\sum_{j=1}^{p} \Gamma_{j}\left(\Delta X_{t-j}-E\left[\Delta X_{t-j}\right]\right)+\varepsilon_{t},
$$

and the equation $\beta^{\prime}\left(X_{t}-E\left[X_{t}\right]\right)=0$ defines the long-run relations between the variables. The VECM model can be estimated by Pseudo Maximum Likelihood

$$
L_{T}(\theta)=-\frac{T k}{2} \log (2 \pi)-\frac{T}{2} \log |\Omega(\theta)|-\frac{1}{2} \operatorname{tr}\left\{\mathrm{E}(\theta)^{\prime} \mathrm{E}(\theta) \Omega(\theta)^{-1}\right\}
$$

where $\theta$ are the parameters of the model, $\mathrm{E}(\theta)$ is the matrix of VECM residuals, $\Omega$ the covariance matrix of the innovations, $t r$ is the trace, and $T$ the sample size. Substituting the optimal $\Omega$, and removing constants the concentrated likelihood can be expressed as

$$
L_{T}(\theta)=-\frac{T}{2} \log \left|\mathrm{E}(\theta)^{\prime} \mathrm{E}(\theta)\right|
$$

Johansen proposed a reduced rank procedure to compute these estimators, and a sequence of maximum likelihood tests to determine empirically the cointegration rank $r$. 